\title{
RUTIN OF Cerasus tianschanica
}

T. K. Chumbalov and Z.S. Dzhumagulova

UDC 547.972

It has been reported previously that the leaves of Cerasus tianschanica Pojark. contain rutin [1].

The results of an investigation of the substance that we isolated has shown that it is a combination of two isomeric forms. To separate the rutins into the isomers we used preparative paper chromatography in the n-butanol-acetic acid-water $(40: 12.5: 29)$ system. The glycosides obtained were purified by chromatography on polyamide sorbent and by crystallization from aqueous methanol. Glycosides (I) and (II) consisted of yellow acicular crystals with $\mathrm{mp} 188-190^{\circ} \mathrm{C},[\alpha]_{\mathrm{D}}^{20}-63.6^{\circ}$ (dimethylformamide), $\lambda \mathrm{C}_{2} \mathrm{H}_{5} \mathrm{OH} 258,265$, and $360 \mathrm{~nm}$, and $\mathrm{mp} 191-192^{\circ} \mathrm{C},[\alpha]_{\mathrm{D}}^{20}-22.9^{\circ}$ (dimethylformamide), $\lambda \underset{\max _{2} \mathrm{H}_{5} \mathrm{OH}}{\mathrm{D}^{2}} 256,260$, and $\max _{360} \mathrm{~nm}$, respectively. In the products of acid hydrolysis $\left(2 \%\right.$ hydrochloric acid, $\left.3 \mathrm{~h}, 100^{\circ} \mathrm{C}\right)$ were found the aglycone quer-

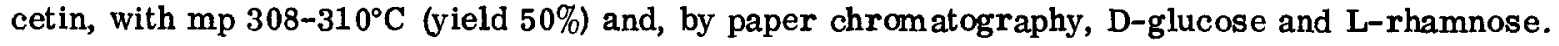

The results of UV spectroscopy with ionizing and complex-forming reagents permitted the assumption that the sugar components in both biosiaes were present at the $\mathrm{C}_{3}$ position of the molecule in the form of bioses [2]. The order of addition of sugars to the aglycone was determined by stepwise hydrolysis $(0.1 \%$ hydrochloric acid).

Bioside (I) was cleaved with the formation as intermediate product of isoquercitrin with $\mathrm{mp} 218^{\circ} \mathrm{C}$, while bioside (II) was hydrolyzed to the aglycone without the formation of an intermediate product under these conditions. The monoside from the bioside (II) was isolated by hydrolysis with $25 \%$ formic acid in cyclohexanol [3], and had $\mathrm{mp} 201-203^{\circ} \mathrm{C}$. The acid hydrolysis of both monosides gave quercetin and glucose, which was attached to the aglycone in the $C_{3}$ position of the molecule. The glucose in the monoside of $(I)$ had the pyranose form of the ring and in the monoside of (II) the furanose form, being attached to the aglycone by a $\beta$-linkage in both cases. The fermentation of the biosides (I) and (II) with rhamnodiastase indicated the linkage of the sugars in the biosides as $1-6$. The bond between the glucose and the rhamnose in the biosides was determined by fermentations with emulsin and with maltase, and the form of the oxide ring of the rhamnose was determined by differential analyses of molecular optical rotation.

Thus, the investigations performed have identified the bioside (I) as isorutin - quercetin 3-O- $[\beta-\mathrm{L}-$

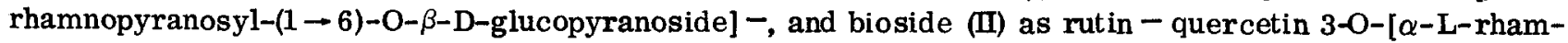
nopyranosyl- $(1 \rightarrow 6)$-O- $\beta$-glucofuranoside]. Similar biosides of quercetin have been described in the literature [4].

\section{LIT ERATURE C IT ED}

1. T. K. Chumbalov and Z.S. Dzhumagulova, Khimiya i Khim. Tekhnologiya, Alna-Ata, No. 9, 146 (1969).

2. L. Jurd, The Chemistry of Flavonoid Compounds, New York (1962), p. 107.

3. D. W. Fox, S. H. Savage, and S. H. Wender, J. Amer. Chem. Soc., 275, 2504 (1963).

4. V. I. Litvinenko and T. P. Nadezhina, Rast. Res., $\underline{6} 8$, No. 4 (1968).

S. M. Kirov State University. Translated from Khimiya Prirodnykh Soedinenii, No. 5, p. 670, September-October, 1973. Original article submitted March 19, 1973.

() 1975 Plenum Publishing Corponation, 227 West 17th Street, New York, N.Y. 10011. No part of this publication may be reproduced, stored in a retrieval system, or transmitted, in any form or by any means, electronic, mechanical, photocopying, microfilming, recording or otherwise, without written permission of the publisher. A copy of this article is available from the publisher for $\$ 15.00$. 